\title{
Compreendendo o Processo de Inclusáo Escolar no Brasil na Perspectiva dos Professores: uma Revisáo Integrativa ${ }^{1}$ Understanding the Process of SChool InCLusion in Brazil from the PERSPECTIVE OF TEACHERS: AN INTEGRATIVE REVIEW
}

\author{
Naiane Cristina SILVA ${ }^{2}$ \\ Beatriz Girão Enes CARVALHO ${ }^{3}$
}

\begin{abstract}
RESUMO: a educação inclusiva garante, por lei, o direito de acolher todas as crianças independentemente de suas condições físicas, intelectuais, sociais, emocionais, linguísticas, dentre outras. $\mathrm{O}$ presente estudo trata-se de uma revisão integrativa que analisou o conteúdo de publicaçôes nacionais do período de janeiro de 2011 a abril de 2016 para compreender quais os facilitadores e as limitaçōes do processo de inclusão escolar no Brasil na visão dos professores. Após busca sistemática no SciELO, LILACS, Web of Science, ERIC, Gale, UFLA, IBICT e Sistema de Bibliotecas da Unicamp, com as palavras-chave: Special Education, Teacher e Brazil*, 16 artigos foram recuperados e lidos na íntegra. Os resultados e discussáo foram apresentados em cinco categorias: 1) concepçôes sobre os recursos e estratégias utilizadas no ensino, 2) a política de educaçáo especial e as capacitaçōes oferecidas pelo poder público, 3) concepçóes sobre o processo de ensino - aprendizado, 4) as lacunas oriundas da formação inicial dos professores e a 5) necessidade de conhecer as especificidades do aluno. Assim, o estudo aponta os fatores que interferem no processo de inclusão escolar, destacando o desconhecimento dos professores sobre a política de inclusão e sobre as capacidades e limitaçóes do aluno no que tange a deficiência e os interesses pessoais, a falta de recursos oferecidos pelo poder público para efetivação de suas açóes, e a falta de profissionais especializados na área de educaçáo especial para o suporte aos professores. Sugerem-se novos estudos sobre as contribuiçôes efetivas dos profissionais de outras áreas na estruturação de recursos e estratégias de apoio a prática educacional.
\end{abstract}

PALAVRAS-CHAVES: Educação Especial. Educação Inclusiva. Capacitação de Professores.

\begin{abstract}
Inclusive education guarantees, by law, the right to receive all children regardless of their physical, intellectual, social, emotional, language conditions, among others. This study is an integrative review that analyzed the national publication content from January 2011 to April 2016 to understand what the facilitators and the limitations of the process of school inclusion in Brazil are from the teachers' view. After systematic search in SciELO, LILACS, Web of Science, ERIC, Gale, UFLA, IBICT and Unicamp Libraries System, with the key words: Special Education, Teacher and Brazil*, 16 articles were retrieved and read in their entirety. The results and discussion were presented in five categories: 1) views on the resources and strategies used in teaching; 2 ) special education policy and training offered by the government; 3) conceptions of the teaching-learning process; 4) the arising gaps in the initial training of teachers; and 5) the need to know the specificities of the student. Thus, this study points to the factors that interfere in the process of school inclusion, highlighting the lack of teachers' knowledge on the inclusion policy, and on the capabilities and limitations of the student regarding disability and personal interests, lack of resources offered by the government for the execution of their actions, and the lack of skilled professionals in the field of special education to support the teachers. Further studies are suggested on the effective contributions of professionals from other areas for structuring resources and strategies to support educational practice.
\end{abstract}

KEYWORD: Special Education. Inclusive Education. Teacher Training.

\footnotetext{
${ }^{1}$ http://dx.doi.org/10.1590/S1413-65382317000200010

Trabalho de Conclusão do Curso de Terapia Ocupacional da Universidade Federal do Triângulo Mineiro - UFTM.

${ }^{2}$ Graduanda do Curso de Terapia Ocupacional da Universidade Federal do Triângulo Mineiro - UFTM. Uberlândia, MG, Brasil. nana_cris_santacity@hotmail.com

${ }^{3}$ Docente do Departamento de Terapia Ocupacional da Universidade Federal do Triângulo Mineiro - UFTM. Uberlândia, MG, Brasil. bgecarvalho@hotmail.com
} 


\section{INTRODUÇÃo}

A educação é considerada direito de todos, dever do Estado e família, sendo promovida e incentivada juntamente com a sociedade, propiciando o desenvolvimento pessoal, o preparo para exercer a cidadania e qualificação para o trabalho (BRASIL, 1988). Pode ser vista também, como um fator de coesão, que deve levar em conta a diversidade dos indivíduos e dos grupos humanos, sendo o respeito pela diversidade e pela especificidade dos indivíduos um princípio fundamental das práticas educativas. Com isso, os sistemas educativos devem ter o respeito pelo pluralismo, com a riqueza das expressóes culturais dos vários grupos sociais que compóem a sociedade, e pela multiplicidade dos talentos individuais (DELORS et al., 1998).

A importância da educação fica expressa na compreensão das políticas públicas brasileiras como o alicerce e a necessidade primária para o cumprimento da cidadania e acesso aos direitos sociais, econômicos, civis e políticos. A Constituição Federal e o Estatuto da Criança e do Adolescente asseguram à população o direito a uma educação de qualidade, compreendida como um processo educativo que leve os educandos a uma formação omnilateral e cidadã (LIMA, 2001). Essa escola de qualidade através de conteúdos e das relaçóes sociais que proporciona, propicia o desenvolvimento humano na sua plenitude, condiçóes de liberdade e dignidade, respeitando e valorizando as diferenças (BRASIL, 2013).

No Brasil, a inclusão é garantida por leis e documentos oficiais, que defendem a criação e execução de políticas públicas para a formação de professores para a educação inclusiva, numa tentativa de diminuir os efeitos da exclusão e atender à nova ordem vigente, que é a de ensinar a todos, sem distinção (ALMEIDA et al., 2007).

A Lei no 9394/96, de 20 de dezembro de 1996, em seu capítulo V, traz educação especial, como uma modalidade de educação escolar, sendo oferecida preferencialmente pelo ensino regular, para alunos com necessidades especiais, oferecendo quando necessário serviço de apoio especializado, para atender às peculiaridades da clientela de educação especial, sendo dever constitucional do Estado, oferecer educação especial (BRASIL, 1996).

Segundo a Declaração de Salamanca (1994), as escolas deveriam acolher todas as crianças independentemente de suas condiçôes físicas, intelectuais, sociais, emocionais, linguísticas ou outras.-

Segundo Mantoan (2006), os sistemas escolares estão formados no princípio que recorta a realidade, dividindo alunos em normais e deficientes, o ensino em regular e especial, e fazendo professores em especialistas sobre diferentes necessidades especiais. Construindo uma lógica com visão determinista, mecanicista, formalista, reducionista própria do pensamento científico moderno, ignorando o subjetivo, afetivo, criador, não conseguindo assim romper o velho modelo escolar, para efetivar a mudança que a inclusão busca.

Deve-se ressaltar que a "educação inclusiva é a aceitação das diferenças, não uma inserção em sala de aula” e que exige transformaçōes no sistema de ensino, envolvendo o respeito às diferenças individuais, a cooperação entre os alunos, professores capacitados para incluir todos os alunos em todas as atividades escolares e, principalmente, trabalhar a questâo do respeito e da dignidade (MOREIRA, 2006). 
Pensar em uma escola inclusiva significa pensar em uma escola para cada um, isto é, em uma escola em que cada aluno seja atendido de acordo com suas necessidades e dificuldades, utilizando os recursos e metodologias que proporcionem o seu aprendizado e desenvolvimento (MIRANDA, 2001).

Deve-se lembrar que a educação inclusiva não envolve apenas governo, leis, escolas e alunos. Lima (2010) refere ser o professor o agente principal, estando mais envolvido e sendo o responsável maior no processo inclusivo e educativo da criança. Silva (2003) aponta que no trabalho de inclusão é preciso envolver também a família como coparticipante no apoio ao aluno, possibilitando assim um trabalho integrado entre escola, família e profissionais. A parceria entre escola inclusiva e família é fundamental no processo de inclusão, a fim de quebrar barreiras na participação e inclusão social das pessoas com necessidades educacionais especiais (RODOVALHO, 2005).

Garcia et al. (2006) destacam que para que um programa de inclusão escolar tenha sucesso, este deverá envolver a família do educando e permitir sua coparticipação na assistência e no desenvolvimento do aluno, possibilitando um trabalho conjunto entre escola, família e profissionais, no qual a família contribui com a escola por meio de informaçóes, sugestóes, críticas e solicitações, que sinalizarão os caminhos que a escola deve seguir.

Além da participação da família para efetivação do processo de inclusão escolar, Silva et al. (2012) trazem que a formação do profissional é o fator principal para a efetivação da escola inclusiva, necessitando que o professor acredite na criança como um ser cognocente e que ele é a principal peça para que a criança se desenvolva, sendo necessário adotar estratégias durante o processo educacional. Estratégias estas que serão elaboradas diante do conhecimento do professor sobre seu aluno, sobre suas capacidades e necessidades, visto que a aprendizagem efetiva promove desenvolvimento, acontecendo por meio da mediação do professor, grupos, instrumentos utilizados e até mesmo de reflexóes sobre os aprendizados anteriores (TOLEDO; MARTINS, 2009).

Durante este processo é necessário que os professores acolham os alunos com necessidades educacionais especiais (NEEs), o que exige deste mudanças em seu comportamento, visando um acolhimento pautado em princípios éticos, igualitários e solidários (TOLEDO; MARTINS, 2009).

Assim, este estudo tem como objetivo compreender quais os facilitadores e as limitaçóes do processo de inclusão escolar na visão dos professores. Ao se estruturar enquanto revisão integrativa de literatura pretende contribuir para a sistematização do conhecimento recente produzido acerca da inclusão escolar e as lacunas neste processo.

\section{Método}

O presente estudo utiliza como método a Revisão Integrativa (RI) da Literatura, que é um método de revisão específica que visa reunir e resumir estudos produzidos anteriormente sobre a temática investigada (BUBLITZ et al., 2012).

Segundo Mendes, Silveira e Galvão (2008), para elaboração deste tipo de estudo as etapas percorridas são: I) Estabelecimento da hipótese ou questão da pesquisa; II) Busca na 
literatura; III) Categorização dos estudos; IV) Avaliação dos estudos incluídos na revisão; V) Interpretação dos resultados; VI) Síntese do conhecimento.

Seguindo-se estas etapas, enfatiza-se o estabelecimento do tema, como a primeira fase para o desenvolvimento da revisão, sendo esta a norteadora para o desenvolvimento do trabalho, pois consiste na etapa de definição dos objetivos a serem alcançados, da definição dos descritores e identificação do tema (MENDES; SILVEIRA; GALVÃO, 2008). Para esta etapa o objetivo da pesquisa consistiu na seguinte questão norteadora: Quais fatores e de que modo estes interferem no processo de inclusão escolar no Brasil na visão dos professores?

Durante a segunda etapa "Busca na literatura", utilizou-se como fontes de levantamento bibliográficos as seguintes bases de dados: Scientific Eletronic Library On-Line (Scielo), Literatura Latino-Americana e do Caribe em Ciências da Saúde (LILACS), Web of Science, Educational Resources Information Center (ERIC), World Scholar: Latin America \& The Caribbean (GALE), Repositório Institucional da Universidade Federal de Lavras (UFLA), Instituto Brasileiro de Informação em Ciência e Tecnologia (IBICT) e Sistema de Bibliotecas da Unicamp. Os descritores selecionados para uma busca completa foram "Brazil", seguido do símbolo*, para serem encontradas palavras com esse radical, "Teacher" e "Special Education". Esses descritores foram selecionados em virtude dos objetivos da pesquisa, dessa forma Brazil* pelo interesse ser apenas em publicações que retratassem a realidade da Educação Especial nesse país, não contemplando ao presente estudo diferentes realidades. $\mathrm{O}$ descritor Teacher devido ao interesse em artigos que trouxessem a visão do professor sobre o processo de educação especial tendo este como ator fundamental do presente estudo. E Special Education foi escolhido por ser o alvo do estudo a compreensão dessa modalidade. O cruzamento realizado foi Brazil* AND Teacher AND Special Education.

Estabeleceram-se como critérios de inclusão para a seleção dos artigos aqueles que estavam disponíveis na íntegra, que relatassem o processo de inclusão escolar no Brasil, sejam estes publicados nos idiomas português, inglês e espanhol e que tenham sido publicados de janeiro de 2011 a abril de 2016. Como critérios de exclusão definidos para seleção de artigos foram: artigos que relatem exclusivamente o processo de inclusão escolar de outros países, em locais fora do âmbito escolar, assim como estudos que durante a leitura na íntegra não traziam informaçóes claras sobre a metodologia, para resposta aos objetivos do presente estudo.

Após o cruzamento dos descritores obteve-se um resultado total de 172 artigos, sendo encontrados no Scielo (67 publicações), na LILACS (43 publicações), no Web of Science (13 publicações), no ERIC (7 publicaçóes), no Gale (2 publicações), na UFLA (19 publicaçóes), na IBICT (6 publicações) e no Sistema de Bibliotecas da Unicamp (15 publicações). Em seguida foi feita a leitura dos resumos, obtendo-se um total de 47 artigos para amostra. Durante a leitura na íntegra e sendo aplicados os critérios de inclusão/ exclusão, delimitou-se a amostra em 16 artigos. Observou-se durante a seleção dos artigos que os principais motivos para exclusão das publicações foram: repetiçôes dos artigos em diferentes bases de dados, não estar diretamente relacionado à temática, principalmente quanto a visão do professor em relação ao tema.

Para a terceira e quarta etapas da RI - Categorização e avaliação dos estudos incluídos na revisão - foi realizada a leitura das publicaçóes e utilizado o instrumento para coleta de dados elaborado por Ursi (2005). O instrumento trata-se de um quadro que contempla os seguintes 
itens: identificação do artigo original, características metodológicas do estudo, avaliação do rigor metodológico, das intervençóes mensuradas e dos resultados encontrados. Foram realizadas adaptaçóes pelas autoras no instrumento na parte de: instituição sede do estudo, tipo de publicação, tipo de amostra, intervenções realizadas e análise, sendo necessário também excluir do instrumento tratamento de dados e nível de evidência.

Nas últimas etapas de "Interpretação dos resultados" e "Síntese do conhecimento"foram compilados os dados do material referente aos facilitadores e limitaçóes do processo de inclusão escolar na visão dos professores, sendo realizada uma análise descritiva que permitiu a categorização de temáticas para o desenvolvimento da composição do conhecimento.

\section{Resultados e discussáo}

A partir da busca realizada foram encontrados 172 publicaçóes, sendo que após a leitura dos resumos obteve-se um total de 47 publicaçóes, no refinamento feito de acordo com os critérios de inclusão e exclusão e leitura na íntegra foram selecionados 16 artigos, disponibilizados em três bases de dados: Scielo (14 artigos), Lilacs (um artigo) e Web of Science (um artigo), conforme Quadro 1.

\begin{tabular}{|c|c|c|c|}
\hline Título do artigo & Autores & Ano & Objetivos \\
\hline $\begin{array}{l}\text { A inclusão do aluno surdo no Ensino } \\
\text { Médio e Ensino Profissionalizante: um } \\
\text { olhar para os discursos dos educadores }\end{array}$ & $\begin{array}{l}\text { Mallmann; Con- } \\
\text { to; Bagarollo; } \\
\text { França }\end{array}$ & 2014 & $\begin{array}{l}\text { Investigar, a partir do olhar da equipe } \\
\text { educacional, as práticas pedagógicas } \\
\text { no Ensino Médio e Ensino Profissio- } \\
\text { nalizante quando tem em sala de aula } \\
\text { um aluno surdo. }\end{array}$ \\
\hline $\begin{array}{l}\text { Atividades de vida autônoma na escola } \\
\text { de tempo integral: aluno com deficiên- } \\
\text { cia visual - perspectivas educacionais }\end{array}$ & Trínanes; Arruda & 2014 & $\begin{array}{l}\text { Buscou conhecer as percepçóes dos } \\
\text { educadores frente à açáo docentes } \\
\text { de aluno com deficiência visual e a } \\
\text { pratica as atividades de vida autônoma } \\
\text { na educaçáo em tempo integral, sob } \\
\text { perspectivas da educaçáo inclusiva. }\end{array}$ \\
\hline $\begin{array}{l}\text { Comunicação alternativa no con- } \\
\text { texto educacional: conhecimento de } \\
\text { professores }\end{array}$ & $\begin{array}{l}\text { Carnevale; Ber- } \\
\text { verian; Moraes; } \\
\text { Kruger }\end{array}$ & 2013 & $\begin{array}{l}\text { Conhecer a visão de professores sobre } \\
\text { a linguagem de alunos com paralisia } \\
\text { cerebral sem fala oralizada encadeada } \\
\text { ou funcional e investigas, também, o } \\
\text { seu conhecimento acerca da Comu- } \\
\text { nicaçáo Alternativa, assim como seus } \\
\text { possíveis usos em sala de aula. }\end{array}$ \\
\hline $\begin{array}{l}\text { Concepçóes de professores da educação } \\
\text { especial (APAES) sobre a aprendizagem } \\
\text { e desenvolvimento do aluno com defi- } \\
\text { ciência intelectual: um estudo a partir } \\
\text { da teoria vigotskiana }\end{array}$ & $\begin{array}{l}\text { Leonel; } \\
\text { Leonardo }\end{array}$ & 2014 & $\begin{array}{l}\text { Identificar concepções de professores } \\
\text { que atuam na educação especial sobre } \\
\text { a aprendizagem e desenvolvimento } \\
\text { de alunos com deficiência intelec- } \\
\text { tual, buscando averiguar como estes } \\
\text { compreendem esse processo, bem } \\
\text { como suas percepçóes sobre o papel da } \\
\text { mediaçáa na aprendizagem; }\end{array}$ \\
\hline
\end{tabular}

(continua) 


\begin{tabular}{|c|c|c|c|}
\hline Título do artigo & Autores & Ano & Objetivos \\
\hline $\begin{array}{l}\text { Concepçóes de professores sobre inclu- } \\
\text { são escolar e interaçôes em ambiente } \\
\text { inclusivo: uma revisão da literatura }\end{array}$ & $\begin{array}{l}\text { Silveira; Enumo; } \\
\text { Rosa }\end{array}$ & 2012 & $\begin{array}{l}\text { Verificar na literatura cientifica nacio- } \\
\text { nal publicada nos últimos dez anos } \\
\text { (2000-2010), na BVS, conteúdo dos } \\
\text { estudos empíricos que tratam da inte- } \\
\text { raçáo entre professores e alunos com } \\
\text { alguma necessidade educativa especial } \\
\text { e/ou das concepçóes acerca da sua } \\
\text { inclusão escolar, identificando possíveis } \\
\text { fatores que facilitam ou dificultam a } \\
\text { eficácia da interação e mediação no } \\
\text { contexto escolar; }\end{array}$ \\
\hline $\begin{array}{l}\text { Demandas de professores decorrentes } \\
\text { da inclusáo escolar }\end{array}$ & Matos; Mendes & 2015 & $\begin{array}{l}\text { Analisar as demandas decorrentes da } \\
\text { educaçáo inclusiva e as possibilidades } \\
\text { de atuação do psicólogo escolar, sendo } \\
\text { o presente trabalho um recorte referen- } \\
\text { te à analise das demandas; }\end{array}$ \\
\hline $\begin{array}{l}\text { Ensino colaborativo para o apoio à } \\
\text { inclusão escolar: praticas colaborativas } \\
\text { entre os professores }\end{array}$ & $\begin{array}{l}\text { Vilaronga; } \\
\text { Mendes }\end{array}$ & 2014 & $\begin{array}{l}\text { Consiste em analisar as experiências } \\
\text { praticas em ensino colaborativo, dos } \\
\text { professores de educação especial do } \\
\text { município de são Carlos - SP, que } \\
\text { participaram de uma formação na } \\
\text { temática no segundo semestre de 2011; }\end{array}$ \\
\hline $\begin{array}{l}\text { Ensino da matemática a alunos com } \\
\text { deficiência intelectual na educação de } \\
\text { jovens adultos }\end{array}$ & $\begin{array}{l}\text { Brito; Campos; } \\
\text { Romanatto }\end{array}$ & 2014 & $\begin{array}{l}\text { Conhecer as praticas do professor da } \\
\text { EJA para o ensino e saberes matemá- } \\
\text { ticos ao aluno jovem e adulto com } \\
\text { deficiência intelectual, e intervir junto } \\
\text { ao docente sobre possíveis estratégias } \\
\text { que seriam, entáo, adotados; }\end{array}$ \\
\hline $\begin{array}{l}\text { Estratégias de ensino e recursos peda- } \\
\text { gógicos para o ensino de alunos com } \\
\text { TDAH em aulas de educaçáo física }\end{array}$ & $\begin{array}{l}\text { Costa; Moreira; } \\
\text { Seabra Júnior }\end{array}$ & 2015 & $\begin{array}{l}\text { Planejar, aplicar e analisar um pro- } \\
\text { grama de intervenção sistematizado, } \\
\text { composto por atividades psicomotoras, } \\
\text { lúdicas e jogos de estratégias a partir } \\
\text { da adaptaçâo de recursos pedagógicos } \\
\text { e estratégias de ensino utilizadas em } \\
\text { aulas de educaçáo física com intuito de } \\
\text { estimular a memoria, atenção e con- } \\
\text { centraçáo de crianças com TDAH. }\end{array}$ \\
\hline $\begin{array}{l}\text { Estratégias pedagógicas empregadas } \\
\text { por professores de educação especial } \\
\text { aos alunos com deficiência intelectual } \\
\text { severa: um estudo descritivo da pratica } \\
\text { docente }\end{array}$ & $\begin{array}{l}\text { Caramori; } \\
\text { Dall'Acqua }\end{array}$ & 2015 & $\begin{array}{l}\text { Pauta-se na descrição e analise da } \\
\text { implantação do processo educacional } \\
\text { de alunos com deficiência intelec- } \\
\text { tual severa, enfocando as estratégias } \\
\text { pedagógicas de professores de educação } \\
\text { especial na cidade de Araraquara. }\end{array}$ \\
\hline
\end{tabular}

(continua) 


\begin{tabular}{|c|c|c|c|}
\hline Título do artigo & Autores & Ano & Objetivos \\
\hline $\begin{array}{l}\text { Formação de professores por meio } \\
\text { de pesquisa colaborativa com vistas } \\
\text { à inclusão de alunos com deficiência } \\
\text { intelectual }\end{array}$ & Toledo; Vitaliano & 2012 & $\begin{array}{l}\text { Investigar a eficácia de um programa } \\
\text { de intervenção por meio de pesquisa } \\
\text { colaborativa junto a professores do } \\
\text { ensino fundamental II, tendo em } \\
\text { vista prepara-los para promover a } \\
\text { inclusão a aluno com DI. }\end{array}$ \\
\hline $\begin{array}{l}\text { Inclusão de alunos com deficiência na } \\
\text { aula de educação física: identificando } \\
\text { dificuldades, açóes e conteúdos para } \\
\text { prover a formação do professor }\end{array}$ & Fiorini; Manzini & 2014 & $\begin{array}{l}\text { Identificar as dificuldades encontradas } \\
\text { por professores de educação física } \\
\text { para atender a demanda da inclusão } \\
\text { educacional de alunos com defici- } \\
\text { ência; Sugerir ações e conteúdos, a } \\
\text { partir dessas dificuldades, que possam } \\
\text { promover a formação do professor de } \\
\text { educação física. }\end{array}$ \\
\hline $\begin{array}{l}\text { Inclusão de crianças com deficiência } \\
\text { na escola regular numa região do } \\
\text { município de São Paulo: conhecendo } \\
\text { estratégias e açóes }\end{array}$ & Briant; Oliver & 2012 & $\begin{array}{l}\text { Conhecer de vista e da percepçáo de } \\
\text { professores do ensino fundamental, as } \\
\text { estratégias que utilizam para favorecer } \\
\text { a inclusão de crianças com deficiência } \\
\text { na classe comum de escola regular. }\end{array}$ \\
\hline $\begin{array}{l}\text { Ingresso e permanência de alunos com } \\
\text { deficiência em universidades públicas } \\
\text { brasileiras }\end{array}$ & Castro; Almeida & 2014 & $\begin{array}{l}\text { Identificar as açóes e iniciativas de } \\
\text { universidades públicas brasileiras } \\
\text { quanto ao ingresso e permanência } \\
\text { de pessoas com deficiência, a fim de } \\
\text { verificar as barreiras e os facilitadores } \\
\text { encontrados por esses estudantes no } \\
\text { cotidiano do ensino superior. }\end{array}$ \\
\hline $\begin{array}{l}\text { O uso de recursos de tecnologia } \\
\text { assistiva por crianças com deficiência } \\
\text { física na escola regular: a percepção dos } \\
\text { professores }\end{array}$ & Alves; Matsukura & 2012 & $\begin{array}{l}\text { Investigar o contexto da escolariza- } \\
\text { çáo no ensino regular do aluno com } \\
\text { paralisia cerebral mais comprometido } \\
\text { motoramente, utilizou-se o sistema de } \\
\text { classificaçáa da função motora grossa } \\
\text { para seleçáo dos alunos inicialmente. }\end{array}$ \\
\hline $\begin{array}{l}\text { Práticas de professores frente ao aluno } \\
\text { com deficiência intelectual em classe } \\
\text { regular }\end{array}$ & Santos; Martins & 2015 & $\begin{array}{l}\text { Investigar práticas pedagógicas de } \\
\text { professores de uma escola de rede mu- } \\
\text { nicipal de Natal/RN, em 2011, frente } \\
\text { a alunos com deficiência intelectual, } \\
\text { matriculados em anos iniciais do } \\
\text { ensino fundamental. }\end{array}$ \\
\hline
\end{tabular}

Quadro 1 - Informaçóes dos artigos obtidas e organizadas pelas autoras.

No que se refere ao ano de publicação, pôde-se constatar maior destaque para o ano de 2014. O presente estudo abrangeu publicaçóes com quatro artigos no ano de 2012, um em 2013, sete em 2014, quatro em 2015.

Dos artigos selecionados para o estudo, ressalta-se que todos são publicações brasileiras e estavam na língua portuguesa. 
Em relação à instituição sede dos estudos houve diferentes locais, como: Escolas de Educação Infantil, Ensino Fundamental, Ensino Médio e Ensino Superior.

As características metodológicas não apresentaram variação dos tipos de estudo, sendo utilizada nos 16 artigos a abordagem qualitativa.

Além da caracterização do estudo, foi realizada uma análise detalhada dos artigos que foram divididos em cinco categorias intencionando mostrar uma síntese da compreensão de quais os facilitadores e as limitaçóes do processo de inclusão escolar na visão dos professores. As categorias elaboradas foram intituladas como: I. Recursos e estratégias de ensino; II. Política de Educação Especial e Capacitaçóes oferecidas pelo poder público; III. Processo de Ensinoaprendizagem; IV. Lacunas oriundas da formação inicial dos professores; V. Conhecimento sobre as especificidades do aluno.

A seguir serão apresentados os resultados e a discussão referentes às categorias elaboradas, frente a perspectiva dos professores sobre o processo de inclusão escolar.

\subsection{Categoria I: Recursos E estratégias de ENSINo}

A partir da análise dos dados verificou-se que os 16 artigos relatam a necessidade da inserção de adaptações e utilização de recursos no ensino objetivando facilitar o processo de inclusão escolar para os alunos com NEEs, para que estes possam participar ativamente do processo de ensino.

Dentre as adaptaçóes necessárias para efetivação deste processo, os professores julgam a necessidade da realização de adequaçóes metodológicas, pedagógicas, de infraestrutura e comunicativas para desenvolvimento do ensino.

Diante das adequações metodológicas necessárias os estudos apontam a necessidade de análise de currículo para realização de modificaçóes, seja para inclusão ou exclusão de determinados conteúdos (MALLMANN et al., 2014; SANTOS; MARTINS, 2015) ou, para adaptações na estrutura curricular de matérias (MATOS; MENDES, 2015), como na prática da educação física (FIORINI; MANZINI, 2014), o que aponta um despreparo no sistema educacional de ensino (SANTOS; MARTINS, 2015), observado nas dificuldades dos professores em elaborar estratégias que permitam que estes alunos com dificuldades compreendam o assunto discutido.

No que se referem às adequações pedagógicas autores como Silveira, Enumo e Rosa (2012) pontuam a necessidade de adequação das tarefas e utilização de atividades pedagógicas alternativas para que os alunos com NEEs tenham acesso ao conhecimento e consequentemente ocorra o processo do seu desenvolvimento. Brito, Campos e Romanatto (2014) apresentaram como adequaçóes nas tarefas a modificação no critério de avaliação e de exposição dos conteúdos ministrados em sala de aula.

Não basta apenas ocorrer a adequação de tarefas, como as citadas acima, é necessário fazer o uso de recursos que permitam facilitar o processo de ensino no decorrer do aprendizado, sejam estes equipamentos de tecnologia assistiva ou recursos materiais ou vivenciados.

Desta forma, Alves e Matsukura (2012) apontam que os professores julgam a necessidade da utilização de recursos pedagógicos práticos, específicos, atrativos ao aluno e que os pos- 
sibilitem superar as suas dificuldades facilitando o caráter geral do trabalho escolar. As autoras apontam como recursos equipamentos de tecnologia assistiva, tais como engrossadores para o uso de lápis, computadores adaptados conforme as necessidades do aluno e o uso da comunicação alternativa que permite promover e ampliar as habilidades das pessoas com limitaçóes funcionais. Porém os professores e auxiliares não recebem orientaçóes quanto à forma de utilização destes recursos, tornando-se assim ineficazes para o processo. Observa-se a necessidade de ajuda de pessoas especializadas para a confecçáo destes equipamentos de tecnologia assistiva, consolidando a necessidade da participação de órgãos da educação e da terapia ocupacional para elaboração e indicação de recursos de tecnologia assistiva (ALVES; MATSUKURA, 2012).

Os recursos devem partir de atividades concretas para experiências cotidianas vivenciadas, sendo possível fazer uso de alfabeto móvel, figuras geométricas, animais, objetos, como também de pessoas, histórias, música, vídeos, dentre outros (LEONEL; LEONARDO, 2014), atividades que estimulem sensorialmente (CARAMORI; DALLACQUA, 2015), ou até mesmo o uso de atividades que tragam desenhos atuais, construção de jogos e brinquedos sendo necessária a mudança dos graus de complexidade das atividades no decorrer do processo (COSTA; MOREIRA; SEABRA JÚNIOR, 2015). Porém Fiorini e Manzini, (2014) referem que a situação atual das escolas é pautada pela inexistência, insuficiência ou pouca variabilidade destes recursos.

Dentre os recursos pedagógicos ainda a serem utilizados para o processo de inclusão escolar, há a possibilidade do uso da fala como incentivador, encorajador, auxiliador nas atividades, auxílios físicos ou concomitantemente o auxilio verbal e físico (COSTA; MOREIRA; SEABRA JÚNIOR, 2015; CARAMORI; DALL' ACQUA, 2015). Outro recurso a ser utilizado é o estabelecimento de regras, rotina e uso da mediação, seja dos professores ou auxiliares ou colegas de sala, podem ser utilizadas também atividades grupais, estas propiciam trocas de experiência e desenvolvimento de cooperação entre os alunos (COSTA; MOREIRA; SEABRA JÚNIOR, 2015; SANTOS; MARTINS, 2015).

A escolha dos recursos e estratégias a serem utilizadas em sala de aula não ocorre aletoriamente. $\mathrm{O}$ professor necessita planejar aula, mas primeiramente deve traçar quais serão as estratégias que este utilizará para ministrar as suas aulas e assim definir quais serão suas açóes (BRIANT; OLIVER, 2012; VILARONGA; MENDES, 2014).

Para efetivação do processo de inclusão escolar, não se deve apenas pensar nos recursos e estratégias a serem utilizados, é necessário ter um olhar mais amplo, um olhar para a estrutura externa do ambiente educacional, como também para o interior da instituição, observando a forma como este aluno chega à escola e como este adentra o prédio.

Silveira, Enumo e Rosa (2012), Triñanes e Arruda (2014), Castro e Almeida (2014) e Matos e Mendes (2015) relatam a necessidade de olhar para a infraestrutura institucional, tornando este um ambiente acessível, sendo desde o ambiente externo institucional até o ambiente interno, como salas, corredores, banheiros, tendo manutenção e restauração destes espaços. Santos e Martins (2015) trazem que entre as maiores dificuldades dos professores em manter suas salas adequadas diante das necessidades dos alunos é a dificuldade destes em organizar a sala de aula, diante da diversidade de casos em um local, já Fiorini e Manzini (2015) apontam a dificuldade em desenvolver suas atividades fazendo uso dos recursos devido à falta de espaço. 
Além do espaço físico, Carnevale et al. (2013), Triñanes e Arruda (2014), Castro e Almeida (2014) apontam as barreiras comunicativas como uma grande dificuldade no processo de inclusão, a inacessibilidade dos alunos sobre as informaçóes expostas dificulta o envolvimento do mesmo na sala de aula. Alves e Matsukura (2012) apontam o uso da comunicação alternativa como algo positivo nesse contexto. A comunicação alternativa permite não apenas expor as informaçóes aos alunos, como também permite que os professores possam entender o que o aluno deseja naquele momento, ou seja, permite que este se comunique com professor e demais profissionais.

Portanto, os estudos mostram a necessidade de olhar para todos os âmbitos da educação inclusiva, tendo a necessidade de verificar e modificar questóes não apenas didáticas (recursos e estratégias de ensino), como também estrutural (ambiente interno e externo da instituição), levando-se em conta a diversidade de casos e especificidades de cada aluno com necessidade educacional especial.

\subsection{Categoria II: Política de educaÇÃo especial E CaPaCitaÇốes oferecidas pelo PODER PÚBLICO}

Os artigos revelaram que alguns professores desconhecem a política de educação especial, portanto apresentam muitas vezes a concepção de inclusão defasada, sendo esta concepção fundamental para garantir o sucesso ou fracasso deste processo, pois a partir do conhecimento da política, o profissional compreende o significado e as possibilidades da inclusão (ALVES; MATSUKURA, 2012; SANTOS; MARTINS, 2015; MATOS; MENDES, 2015).

Mostra-se que os professores e outros profissionais não são capacitados na área de inclusão escolar e apresentam falta de engajamento filosófico e político para atender às diretrizes desse novo paradigma que é a inclusão, apresentando dúvidas conceituais, falta de clareza e indagaçōes relevantes sobre a política (TRIÑANES; ARRUDA, 2014; MATOS; MENDES, 2015). Portanto percebe-se a necessidade de reconstruir o saber destes professores e ampliar a formação dos mesmos na área (BRIANT; OLIVER, 2012).

Briant e Oliver (2012) e Matos e Mendes (2015) relatam sobre a carência no oferecimento de cursos de capacitação sobre inclusão pelo poder público e que quando oferecidos, alguns destes são inadequados ou insuficientes para uma prática efetiva. Sendo necessário o acontecimento de capacitaçóes para os professores e demais profissionais que compóem a equipe de educação inclusiva, pois esta traz benefícios ao desenvolvimento do trabalho destes profissionais (SILVEIRA; ENUMO; ROSA, 2012; VILARONGA; MENDES, 2014).

Desta forma, observa-se a necessidade de conhecimento sobre a política de educação inclusiva, os seus determinantes e suas práticas, para que assim constitua-se um processo de inclusão eficaz e que englobe todos. Em contrapartida nota-se a necessidade de consolidar uma prática social que encoraje escola, família e alunos a reverem comportamentos e crenças, permitindo uma facilitação entre a articulação de programas e políticas (SILVEIRA; ENUMO; ROSA, 2012), estabelecendo, assim, uma inclusão não apenas educacional, mas também social, garantindo as necessidades dos alunos. 


\subsection{Categoria III: Processo de ensino - aprendizagem}

Nesta categoria os artigos expóem os fatores que contribuem para o processo de inclusão escolar, sendo eles a necessidade da presença de outros profissionais especializados, a busca do conhecimento da Língua Brasileira de Sinais (Libras), no caso da inclusão do aluno surdo, necessidade de reflexóes diárias entre as equipes sobre a prática pedagógica desenvolvida.

Silveira, Enumo e Rosa (2012), Toledo e Vitaliano (2012), Briant e Oliver (2012), Triñanes e Arruda (2014), Vilaronga e Mendes (2014), Matos e Mendes (2015) e Costa Moreira e Seabra Júnior (2015) apontam a importância de compreender, a princípio, o processo de inclusão escolar, objetivando fazer o planejamento da aula antes de entrar em sala de aula facilitando estabelecer as estratégias e os recursos a serem utilizados. Também apontam a importância da equipe escolar composta por professores e profissionais da educação especial, a fim de possibilitar a discussão e reflexão com a equipe sobre a prática pedagógica e situaçóes do cotidiano escolar, bem como o recebimento de orientaçóes mais específicas.

Em contrapartida, Briant e Oliver (2012), Alves e Matsukura (2012), Toledo e Vitaliano (2012), Vilaronga e Mendes (2014), Matos e Mendes (2015) e Santos e Martins (2015) trazem que algumas escolas ou coordenações não estão preocupadas em ter equipes com profissionais especializados, com cuidadores ou auxiliares e professores capacitados para atenderem em salas com recursos multifuncionais e família, como também não se preocupam em informar previamente os professores sobre a matrícula de um aluno com NEES, para que este possa se preparar para o estabelecimento de práticas inclusivas.

Observa-se que este planejamento do professor ou das equipes com profissionais especializados pode não acontecer ocasionando assim a exclusão destes alunos com necessidades educacionais especiais, como também a não utilização de recursos que possibilitem englobar todos na perspectiva da inclusão escolar, permitindo isolamentos de alguns ou atividades diferenciadas e sem proposição pedagógica adequada ao currículo escolar.

Alves e Matsukura (2012), Mallmann et al. (2014), Santos e Martins (2015) e Costa, Moreira e Seabra Júnior (2015) discutem que inclusão educacional proporciona o estabelecimento da inclusão social, sendo que as atividades desenvolvidas em sala de aula contribuem para que todos possam aprender a matéria e assim auxiliar os alunos com NEEs, proporcionando as práticas de amizade e de trabalho cooperativo, não só entre eles, mas também entre aluno e professor. Silveira, Enumo e Rosa (2012) exemplificam essa afirmação trazendo o relato de estudo em que alunos com deficiência auditiva tendiam a se ajudar diante das dificuldades apresentadas por eles durante o aprendizado, por exemplo, aqueles que têm menor perda auditiva desempenham o papel de intérprete e facilitador nas aulas.

Por isto, devem-se planejar atividades iniciais, para além dos conteúdos acadêmicos, que permitam discutir as características que nos fazem diferentes e semelhantes dos outros, que enfoquem a empatia como o respeito à vez da fala da outra pessoa e estar atento à fala do outro, minimizando a rejeição e solidão vivenciada pelos alunos com NEES (TOLEDO; VITALIANO, 2012; SILVEIRA; ENUMO; ROSA, 2012; COSTA; MOREIRA; SEABRA JÚNIOR, 2015). Santos e Martins (2015) discutem que tanto atividades intra e extracurriculares contribuem para participação e engajamento de todos os alunos. 
Alves e Matsukura (2012), Carnevale et al. (2013) e Mallmann et al. (2014) apontam que dentre as várias dificuldades apresentadas pelos professores e demais profissionais que atuam na educação especial, a principal é a dificuldade em comunicar-se com o aluno ou interpretá-lo em certas situações. Como exemplo, o não conhecimento de Libras, como facilitador da interação e desenvolvimento do aluno surdo, como também a presença de um intérprete em sala de aula (SILVEIRA; ENUMO; ROSA, 2012; MALLMANN et al., 2014; CASTRO; ALMEIDA, 2014). Outra dificuldade encontrada é a dificuldade da participação dos alunos com NEES, seja por eles não aceitarem as atividades da forma como estão adaptadas ou os recursos, ou apenas não quererem participar ou não compreenderem as atividades (FIORINI; MANZINI, 2014).

A família é o primeiro grupo social em que a criança está inserida, sendo esta a responsável por tomar as decisóes, enquanto a criança não atinge a maioridade. Portanto, quando as crianças entram no ambiente escolar, é a família que toma as decisóes sobre a participação destas ou náo nas atividades propostas pelos professores. Fiorini e Manzini (2014) discutem que algumas famílias tornam-se um empecilho para efetivação do processo de inclusão escolar, pois estas não aceitam a deficiência da criança e desta forma, não aceitam que seus filhos participem das atividades da forma que estão sendo sugeridas.

Sendo assim, podemos apontar a necessidade de trabalhar em conjunto com os pais e responsáveis, pois a atitude dos pais é um dos fatores que dificulta ou impossibilita o êxito da inclusão escolar, sendo as crenças parentais um dos determinantes para a implementação do programa de inclusão escolar. Portanto, o sucesso da inclusão escolar requer que a comunidade acredite na competência das escolas em atender às necessidades de todos os estudantes. Os pais precisam ter confiança na capacidade de as instituiçóes educarem alunos com ou sem necessidades especiais em conjunto (BARBOSA; ROSINI; PEREIRA, 2007).

\subsection{CATEGORIA IV: LACUNAS ORIUNDAS DA FORMAÇÁO INICIAL DOS PROFESSORES}

Os artigos referentes a esta categoria abordam a carência na formação de um professor frente à atuação com alunos com NEEs, observando um despreparo em sua atuação, seja referente ao conhecimento teórico ou de atuação prática (BRIANT; OLIVER, 2012; TOLEDO; VITALIANO, 2012; SILVEIRA; ENUMO; ROSA, 2012; MALLMANN et al., 2014; FIORINI; MANZINI, 2014; MATOS; MENDES, 2015). Os professores trazem que este despreparo de conhecimento necessário para vencer as dificuldades oriundas da prática com aluno com NEES, torna-se um empecilho para transmissão do conhecimento, pois o mesmo não contém este saber, desta forma não seria possível transmiti-lo (LEONEL; LEONARDO, 2014).

Este despreparo não só é oriundo da falha de sua formação, como também das especificidades da educação especial, gerando certas vezes o sentimento de angústia e medo nestes professores, sobre sua capacidade de transmissão de conhecimento, para o aprendizado efetivo do outro (SILVEIRA; ENUMO; ROSA, 2012).

Portanto, vê-se a necessidade de incentivar e melhorar a formação dos professores, pois assim estes se sentem mais capazes e seguros para transmitirem o conhecimento, como também para identificar as necessidades e capacidades de um aluno com NEES (CASTRO; ALMEIDA, 2014). 


\subsection{Categoria V: Conhecimento sobre as especificidades do aluno}

Através dos artigos desta categoria foi possível concluir a importância de compreender as necessidades e as capacidades de cada aluno com NEEs para que desta forma seja possível identificar quais serão as adaptações, estratégias utilizadas para o ensino deste aluno e de que modo serão ministradas as aulas, atendendo assim suas necessidades, pois na falta de conhecimento sobre o aluno é impossível desenvolver atividades que respondam às suas especificidades (TOLEDO; VITALIANO, 2012; VILARONGA; MENDES, 2014; CASTRO; ALMEIDA, 2014; MATOS; MENDES, 2015; COSTA; MOREIRA; SEABRA JÚNIOR, 2015; CARAMORI; DALL' ACQUA, 2015).

Os autores relatam sobre a importância de conhecer não apenas a deficiência que o aluno tem, mas também conhecer sobre sua personalidade, vontades, desejos, ou seja, questóes que vão além de aspectos físicos e biológicos. Portanto, vê-se a importância de conhecer não apenas a deficiência do aluno, como também conhecer sobre sua personalidade o seu "eu", reconhecendo seus princípios, desejos e demais características pessoais. Esse conhecimento proporciona a proposta de atividades que sejam mais adequadas às capacidades, interesses e necessidades. A falta deste conhecimento pessoal e físico do aluno pode gerar dúvidas sobre a real capacidade de aprendizado do aluno, os professores, e demais profissionais, podem se questionar sobre a possibilidade de ensino deste, impactando no término do desenvolvimento de suas potencialidades (CARAMORI; DALL' ACQUA, 2015; SANTOS; MARTINS, 2015).

Castro e Almeida (2014) apontam a importância do desenvolvimento de açóes em prol dos alunos, que permitam oferecer atendimentos diferenciados conforme as suas necessidades e capacidades, assim como oferecer diferentes tipos de apoio que lhes sejam necessário, tais como atendimentos que visem questóes de sua deficiência ou de questóes pessoais são fatores também facilitadores de permanência de alunos com NEES no ambiente institucional de ensino superior (CASTRO; ALMEIDA, 2014).

Observa-se, assim que não conhecer as especificidades do aluno, tem um impacto em cadeia, gerando propostas de ensino inadequadas, consequente não desenvolvimento de suas potencialidades e como última linha do processo, a evasão escolar. O desenvolvimento de açóes institucionais estruturadas com base no conhecimento do aluno permite que o número de evasão do ambiente institucional reduza.

Podemos apontar que nenhum artigo relatou sobre questóes de vulnerabilidade socioeconômica, aspectos comportamentais, seja dos alunos ou dos seus familiares e a forma como estes aspectos interferem no processo de inclusão e permanência do aluno no ambiente educacional.

\section{Conclusão}

Através da RI conclui-se que existem evidências sobre facilitadores e limitaçôes do processo de inclusão escolar na visão dos professores. Os resultados apontam a importância de um olhar amplo sobre a educação inclusiva e a grande necessidade de adaptações para a efetivação deste processo. Foram poucas as publicações que explicitaram sobre os sentimentos vivenciados pelos professores frente às dificuldades oriundas do processo de inclusão escolar. Sendo apontados na maioria dos artigos apenas os aspectos técnicos fundamentais para a efeti- 
vação do ensino aprendizagem de alunos com NEEs, não dando enfoque para os sentimentos dos professores neste processo.

Evidencia-se a falta de apoio que as instituiçóes dão para que a política de inclusão escolar seja cumprida, ocasionando que os professores não estejam capacitados para atuar ou não tenham quantidade suficiente e eficaz de recursos e estratégias. Assim como a não compreensão dos professores sobre a política de educação especial.

Aponta-se a importância da presença de profissionais especializados para dar suporte aos professores, seja para confecção e adaptação dos recursos e estratégias, como para conhecer a deficiência e necessidades pessoais de cada aluno.

Ressalta-se a escassez de estudos nacionais sobre a temática e a atuação de profissionais de outras áreas, como a da saúde, exemplificando os Terapeutas Ocupacionais, na Educação Inclusiva. Dessa forma considera-se a importância de investimentos com estudos sobre as contribuiçóes que os profissionais da área da saúde podem dar pensando na relação entre recurso terapêutico e a prática educacional.

\section{REFERÊNCIAS}

ALMEIDA, D. B. et al. Política educacional e formação docente na perspectiva da inclusão. Educação (UFSM), Santa Maria, v.32, n.1, p.327-342, 2007.

ALVES, A.C. J.; MATSUKURA, T.S. O uso de recursos de tecnologia assistiva por crianças com deficiência física na escola regular: a percepção dos professores. Cadernos de Terapia Ocupacional UFSCar, v.20, n.3, p.381-392, 2012.

BARBOSA, A.J.G.; ROSINI, D.C.; PERREIRA, A.A. Atitudes parentais em relação a educação inclusiva. Revista Brasileira de Educação Especial, v.13, n.3, p.447-458, 2007.

BRASIL. Ministério da Educação. Secretaria de Educação Básica. Secretaria de Educação Continuada, Alfabetização, Diversidade e Inclusão. Conselho Nacional da Educação. Diretrizes Curriculares Nacionais Gerais da Educação Básica. Ministério da Educação. Secretária de Educação Básica. Diretoria de Currículos e Educação Integral. Brasília, DF: MEC, SEB, DICEI, 2013. Disponível em: <http:// portal.mec.gov.br/index.php?option=com_docman\&view=download\&alias=13677-diretrizeseducacao-basica-2013-pdf\&Itemid=30192>. Acesso em: 12 abr. 2015.

BRASIL. Lei no 9.394, de 20 de dezembro de 1996. Estabelece as diretrizes e bases da educação nacional. Presidência da República. Casa Civil. Subchefia de assuntos jurídicos, Brasília, DF, 20 dez. 1996. Disponível em: <http://www.planalto.gov.br/ccivil_03/leis/L9394.htm >. Acesso em: 5 abr. 2015.

BRASIL. Constituição Federal da República Federativa do Brasil de 1988. Presidência da República. Casa Civil. Subchefia de assuntos jurídicos, Brasília, DF, 5 out. 1988. Tit. VIII, Cap. III, Sec. I. Disponível em: <http://www.planalto.gov.br/ccivil_03/Constituicao/Constituicao.htm>. Acesso em: 2 abr. 2015.

BRIANT, M.E.P.; OLIVER, F.C. Inclusão de crianças com deficiência na escola regular numa região do município de São Paulo: conhecendo estratégias e ações. Revista Brasileira de Educação Especial, Marília, v.18, n.1, p.141-154, 2012.

BRITO, J.; CAMPOS, J.A.P.P.; ROMANATTO, M.C. Ensino da matemática a alunos com deficiência intelectual na educação de jovens e adultos. Revista Brasileira de Educaçâo Especial, Marília, v.20, n.4, p.525-540, 2014. 
BUBLITZ, S. et al. Estresse em estudantes de enfermagem: uma revisão integrativa. Revista Enfermagem UFSM, v.2, n.3, p.530-538, 2012.

CARAMORI, P.M.; DALL'ACQUA, M.J.C. Estratégias pedagógicas empregadas por professores de educação especial aos seus alunos com deficiência intelectual severa: um estudo descritivo da prática docente. Revista Brasileira de Educação Especial, Marília, v.21, n.4, p.367-378, 2015.

CARNEVALE, L.B. et al. Comunicação Alternativa no contexto educacional: conhecimento de professores. Revista Brasileira de Educação Especial, Marília, v.19, n.2, p.243-256, 2013.

CASTRO, S.F.; ALMEIDA, M.A. Ingresso e permanência de alunos com deficiência em universidades públicas brasileiras. Revista Brasileira de Educação Especial, Marília, v. 20, n.2, p.179-94, 2014.

COSTA, C.R.; MOREIRA, J.C.C.; SEABRA JÚNIOR, M.O. Estratégias de ensino e recursos pedagógicos para o ensino de alunos com TDAH em aulas de educação física. Revista Brasileira de Educação Especial, Marília, v.21, n.1, p.111-126, 2015.

DECLARAÇÃO DE SALAMANCA. Sobre princípios, políticas e práticas na área das necessidades educativas especiais. Salamanca-Espanha, 1994. Disponível em: <http://portal.mec.gov.br/seesp/ arquivos/pdf/salamanca.pdf>. Acesso em: 2 abr. 2015.

DELORS, J. et al. Educação um tesouro a descobrir: Relatório para a UNESCO da comissão internacional sobre educação para o século XXI. 2.ed. Brasília, DF: Cortez Editora, 1998.

FIORINI, M.L.S.; MANZINI, E.J. Inclusão de alunos com deficiência na aula de educação física: identificando dificuldades, açóes e conteúdos para prover a formação do professor. Revista Brasileira de Educação Especial, Marília, v.20, n.3, p.387-404, 2014.

GARCIA, L.B. et al. Reflexôes sobre o processo de inclusão escolar na perspectiva da família. Temas sobre Desenvolvimento, v.15, n.87-88, p.21-5, 2006.

LEONEL, W.H.S.; LEONARDO, N.S.T. Concepçôes de professores da educação especial (APAEs) sobre a aprendizagem e desenvolvimento do aluno com deficiência intelectual: um estudo a partir da teoria Vigotskiana. Revista Brasileira de Educação Especial, Marília, v.20, n.4, p.541-554, 2014.

LIMA, M. Educação de qualidade: diferentes visôes. Revista Brasileira de Educação, Rio de Janeiro, n.16, p.128-131, 2001.

LIMA, H.T.S. O papel do professor no contexto inclusivo: uma reflexão a partir da teoria de subjetividade. E-Revista Facitec, v.4, n.1, 2010.

MALLMANN, F.M. et al. A inclusão do aluno surdo no ensino médio e ensino profissionalizante: um olhar para os discursos dos educadores. Revista Brasileira de Educação Especial, Marília, v. 20, n.1, p.131-146, 2014.

MANTOAN, M.T.E. Igualdade e diferenças na escola: como andar no fio da navalha. In: MANTOAN, M.T.E.; PRIETO, R.G. (Org.). Inclusão escolar. São Paulo: Summus, 2006.

MATOS, S.N.; MENDES, E.G. Demandas de professores decorrentes da inclusão escolar. Revista Brasileira de Educação Especial, Marília, v.21, n.1, p.9-22, 2015.

MENDES, K.D.S.; SILVEIRA, R.C.C.P.; GALVÃO, C.M. Revisão integrativa: método de pesquisa para a incorporação de evidências na saúde e na enfermagem. Texto \& Contexto-Enfermagem, v.17, n.4, p.758-764, 2008.

MOREIRA, M. A inclusão do deficiente auditivo usuário de implante coclear: um olhar familiar à luz da legislação. Construindo o Serviço Social, n.16, p.59-87, 2006. 
MIRANDA, M.J.C. Educação, deficiência e inclusão no município de Maringá. 2001. Dissertação (Mestrado em Educação) - Universidade Estadual de Maringá, Maringá, 2001. Disponível em: <http://www.portalanpedsul.com.br/admin/uploads/2002/Educacao,_cidadania_e_intercultura/ Trabalho/02_33_56_t877.pdf>. Acesso em: 3 abr. 2015.

SANTOS, T.C.C.; MARTINS, L.A. R. Práticas de Professores Frente ao Aluno com Deficiência Intelectual em Classe Regular. Revista Brasileira de Educação Especial, Marília, v.21, n.3, p.395-408, 2015. SILVA, A.C. Escola e família: uma parceria em prol da escola inclusiva. Fórum Crítico da Educação Revista do ISEP, v.1, n.2, p.41-55, 2003.

SILVA, A.C. et al. Concepçóes de professores da rede publica de ensino sobre inclusão escolar. Revista EFDeportes.com [Revista Digital], Buenos Aires, v.16, n.164, 2012.

SILVEIRA, K.A.; ENUMO, S.R.F.; ROSA, E.M. Concepçôes de professores sobre inclusão escolar e interaçóes em ambiente inclusivo: uma revisão da literatura. Revista Brasileira de Educação Especial, Marília, v.18, n.4, p.695-708, 2012.

RODOVALHO, J.X. Ensino especial e educação inclusiva: direito dos portadores de necessidades educativas especiais. Revista Cientifica Ciência e Cultura, n.2, p.77-85, 2005.

TOLEDO, E.H.; MARTINS, J.B. A atuação do professor diante do processo de inclusão e as contribuiçóes de Vygotsky. In: CONGRESSO NACIONAL DE EDUCAÇÃO-EDUCERE, 9. / ENCONTRO SUL BRASILEIRO DE PSICOPEDAGOGIA-ESBP-ABPP, 3., 2009, Curitiba. Anais eletrônicos... Curitiba: Pontifícia Universidade Católica do Paraná, 2009. Disponível em: <http://www.pucpr.br/ eventos/educere/educere2009/anais/pdf/3298_1675.pdf>. Acesso em: 02 abr. 2015.

TOLEDO, E.H.; VITALIANO, C.R. Formação de professores por meio de pesquisa colaborativa com vistas à inclusão de alunos com deficiência intelectual. Revista Brasileira de Educação Especial, Marília, v.18, n.2, p.319-336, 2012.

TRIÑANES, M.T.R.; ARRUDA, S.M.C. P. Atividades de vida autônoma na escola de tempo integral: aluno com deficiência visual - perspectivas educacionais. Revista Brasileira de Educação Especial, Marília, v.20, n.4, p.581-590, 2014.

URSI, E.S. Prevenção de lesões de pele no perioperatório: revisão integrativa da literatura. 2005. 130 f. Dissertação (Mestrado em Enfermagem) - Escola de Enfermagem de Ribeirão preto, Universidade Estadual de São Paulo, Ribeirão Preto, 2005. Disponível em: <http://www.teses.usp.br/teses/ disponiveis/22/22132/tde-18072005-095456/pt-br.php>. Acesso em: 2 abr. 2015.

VILARONGA, C.A.R.; MENDES, E.G. Ensino colaborativo para o apoio à inclusão escolar: práticas colaborativas entre os professores. Revista Brasileira de Estudos Pedagógicos, v.95, n.239, p.139-151, 2014.

Recebido em: 16/11/2016

Reformulado em: 25/03/2017

Aprovado em: 30/03/2017 